\title{
Editorial: The First Rothkopf Rankings of Nonacademic Organizations
}

\author{
Ronald D. Fricker Jr. \\ Operations Research Department, Naval Postgraduate School, Monterey, California 93943, \\ rdfricker@nps.edu
}

\begin{abstract}
This paper presents the first rankings of nonacademic organizations according to their contributions to the INFORMS practice literature. Two rankings are given, each based on a different metric: visibility is the number of authors who list an organization as their primary affiliation; yield is the equivalent number of INFORMS practice papers attributable to each organization based on author primary affiliation. For the visibility rankings, IBM comes in first place, followed by Hewlett-Packard in second, the US Government in third, and General Electric in fourth place. These are followed by Sasol, Procter \& Gamble, and Merrill Lynch. For the yield rankings, the US Government comes in first place, followed by General Electric and IBM tied for second, and Hewlett-Packard in fourth place. They are followed by Intel in fifth, Procter \& Gamble in sixth, and Merrill Lynch in seventh place.
\end{abstract}

Key words: professional: comments on.

History: Published online in Articles in Advance October 25, 2012.

$\mathrm{R}$ oughly every two years, starting in 1996, Interfaces has published rankings of universities' contributions to the INFORMS practice literature (Rothkopf 1996, 1997, 1999, 2002, 2004, 2005, 2007; Fricker 2009, 2011). Now called the Rothkopf Rankings, in honor of Mike Rothkopf who founded them, the purpose of the rankings is to recognize those academics and academic institutions concerned with and active in operations research/management science (OR/MS) practice, and to thereby encourage such research.

In this paper, I introduce new rankings for nonacademic organizations: corporations, not-for-profit entities, and government organizations. The motivation for these rankings differs somewhat from the university rankings where, almost by definition, research in the nonacademic realm is and should be about the practice of OR/MS. Hence, these rankings are not motivated by the idea of encouraging more applications in industry, but rather encouraging industry to publish more applications in the INFORMS practice literature.

Some of the reasons companies may already encourage publication include increasing external visibility, perhaps to help recruit great talent, and increasing the probability of winning external research grants, especially from government organizations. Hopefully, these rankings enhance these types of publication effects. However, I also hope that for nonacademic individuals who regularly publish, the rankings provide additional visibility within their organizations of their professional contributions to the literature. I also hope the rankings provide an additional incentive to those in the nonacademic community to publish over and above whatever other benefits may accrue from the publication of their work.

\section{Methodology}

I have attempted to keep the ranking methodology for nonacademic organizations as similar to the university rankings as possible. Thus, I count papers in Interfaces and in the OR Practice section of Operations Research. Unrefereed Interfaces columns are counted as half papers. Also following the university rankings, these rankings are based on the most recent seven years of publications-in this case, 2005 to 2011. In the next university rankings (to be published in 2013), practice papers in Decision Analysis and Manufacturing $\mathcal{E}$ Service Operations Management will also be counted. To make these rankings consistent with "The Ninth 
Rothkopf Rankings of Universities' Contributions to the INFORMS Practice Literature" (Fricker 2011), I do not include those journals here, but will include them in the next nonacademic organization rankings.

As with the university rankings, two metrics (one for visibility and the second for yield) result in two rankings. The visibility metric is the number of times a nonacademic organization is listed as the primary affiliation by the authors. No weighting for number of coauthors or any other factor is applied, with the exception that I count Interfaces columns as half papers. The yield metric is the number of papers attributable to each organization, based on author primary affiliation, with credit for each paper uniformly divided among the coauthors, and with Interfaces columns counted as half papers. See Fricker (2009, 2011) for additional discussion about the metrics.

The most significant deviation from the university rankings is that I do not attempt to distinguish between (and thus separately rank) US and non-US organizations. There are two reasons for this. First, given that most large corporations are multinational, it seems to me that segregating them in such a fashion would be artificial at best. Second, I have neither the resources nor interest in doing the research necessary to definitively make such a determination for every nonacademic organizational affiliation listed in Interfaces.

Note that these rankings are based on the parent organization, rather than subsidiaries, divisions, or other subordinate organizations, whenever the parent organization is readily identifiable from the author's affiliation. For example, from 2005 to 2011, authors employed by IBM listed affiliations such as IBM Corporation, IBM Deutschland Research and Development GmbH, IBM Thomas J. Watson Research Center, IBM Software Group, IBM Systems and Technology Group, and IBM Global Business Services, all of which I simply attribute to IBM, the parent company. Similarly, authors employed by General Electric (GE) listed affiliations such as General Electric Global Research Center and GE Capital.

In addition, over the past seven years Interfaces authors have been affiliated with a variety of US government organizations: US Department of Health and Human Services, Centers for Disease Control and Prevention, Transportation Security Administration,
US Postal Service, Federal Aviation Administration, US Environmental Protection Agency, US Geological Survey, USDA Forest Service, US Army, US Air Force, and the US Coast Guard. I include all these organizations under their parent organization, the US Government. Various individual US state and local government organizational affiliations and other non-US national governmental organizations were also included; these I left listed separately because more than one per government affiliation (e.g., for Australia, the Defence Science and Technology Organisation) was never present for 2005-2011.

\section{Results}

I compiled data for 162 papers and columns that were published from 2005 to 2011 and had at least one nonacademically affiliated author. These consisted of 7 OR Practice papers published in Operations Research, 146 papers published in Interfaces, and 9 Interfaces columns. The 162 papers and columns had 508 nonacademically affiliated authors (of 717 authors). Of the 508 listed authors, 457 individuals appeared only as an author on one paper or column, whereas 21 individuals appeared as authors on at least two papers and (or) columns. As Table 1 shows, the 478 unique nonacademic authors were from 28 countries.

\section{Visibility}

Visibility is the number of times an organization appears in print associated with an author. To calculate visibility, for each of the 508 authors of the 162 papers, I simply sum the number of times an organization is listed as an author's primary affiliation from 2005 through 2011. In so doing, I count coauthorship equally whether an individual was the sole author

$\begin{array}{llll}\text { Argentina } & \text { Australia } & \text { Belgium } & \text { Brazil } \\ \text { Canada } & \text { Chile } & \text { China } & \text { Colombia } \\ \text { Costa Rica } & \text { France } & \text { Germany } & \text { Greece } \\ \text { India } & \text { Italy } & \text { Mexico } & \text { New Zealand } \\ \text { Norway } & \text { Poland } & \text { South Africa } & \text { Spain } \\ \text { Sweden } & \text { Switzerland } & \text { Taiwan } & \text { The Netherlands } \\ \text { Turkey } & \text { United Kingdom } & \text { United States } & \text { Venezuela }\end{array}$

Table 1: From 2005 to 2011, 478 nonacademically affiliated authors from the 28 countries listed above published 162 OR practice papers and columns in Interfaces and Operations Research. 
or collaborated with others either within or outside of the author's organization. No weighting for number of coauthors or any other factor has been applied, with the exception of counting Interfaces columns as half papers.

For example, if three authors from Mega Corporation collaborated on an Interfaces paper, Mega Corporation is counted three times in the visibility rankings for that year. Similarly, if the three individuals are authors on three separate Interfaces papers (possibly with collaborators from other organizations), Mega Corporation is still counted three times.

Table 2 shows the results for the top 49 nonacademic organizations that have seven-year scores of 3.0 or higher. Here we see that the top four organizations have noticeably higher seven-year scores than the other 45 organizations. IBM is in first place, followed by Hewlett-Packard in second, the US Government in third, and General Electric in fourth place. These are followed by Sasol, Procter \& Gamble, and Merrill Lynch.

\section{Yield}

Yield is the number of papers attributable to each organization. To quantify yield, I sum the number of times an organization is listed as an author's primary affiliation from 2005 through 2011, weighted by the inverse of the number of coauthors. For example, for a paper with one author, that author's organization receives full credit for the paper; for papers with two coauthors, each organization listed as the primary affiliation is given half credit; for a paper with three coauthors, each organization listed as the primary affiliation is given one-third credit. No other weighting is applied, with the exception of counting Interfaces columns as half papers.

Table 3 shows the results for the top 24 organizations that have seven-year scores higher than 1.0. This can be interpreted as organizations that published the equivalent of at least one INFORMS practice paper over the seven-year period. In this ranking, we see that the same four organizations that top the visibility rankings also top the yield rankings, but in a different order. The US Government comes in first place, followed by General Electric and IBM tied for second, and Hewlett-Packard in fourth place. These are followed by Intel in fifth, Procter \& Gamble in sixth, and Merrill Lynch in seventh place.

\section{Discussion}

Expanding on Rothkopf's seminal work, this paper ranks nonacademic organizations according to their contributions to the INFORMS practice literature in terms of visibility (the number of times an organization is listed as the primary affiliation in the INFORMS practice literature) and yield (the equivalent number of INFORMS practice papers attributable to each organization based on author primary affiliation). It is my intention to produce these rankings of nonacademic organizations every two years, alternating each year between it and the university rankings. As with the university rankings, two years from now these rankings will begin to include practice papers from Decision Analysis and Manufacturing \& Service Operations Management.

In this First Rothkopf Rankings of Nonacademic Organizations, we find that the same four organizations occupy the top four positions in both visibility and yield, although the ordering varies. This can be explained by variations in the number of authors on papers. For example, IBM ranks first in visibility; from 2005 to 2011, it had 31 authors listed on seven Interfaces papers and one Interfaces column, thus giving it a visibility score of 30.5. However, of these 31 authors, 12 were listed on one paper and 10 on another, resulting in a paper yield for IBM of 4.55, which ties it for second place in the yield rankings. In contrast, the US Government ranks third in visibility; from 2005 to 2011, it had 26 authors on 14 Interfaces papers, thus giving it a visibility score of 26 . However, the 14 papers each tended to have fewer total authors, resulting in a yield score of 5.84 .

It is interesting to compare the results in Tables 2 and 3 with the equivalent university ranking results (Fricker 2011). Although they are off by one year (the most recent university rankings are for 20042010), the Ninth Rothkopf Rankings of Universities included 541 academic authors from 26 countries, whereas this ranking on nonacademic organizations includes 508 nonacademic authors from 28 countries. Similarly, there were 56 universities (US and non-US combined) with visibility rankings of 3.0 or higher compared to 49 nonacademic organizations in these rankings. These statistics are quite close.

However, when looking at the yield rankings, there were 70 universities with yield scores of 1.0 or 


\begin{tabular}{|c|c|c|c|c|c|c|c|c|c|}
\hline \multirow[b]{2}{*}{ Organization } & \multicolumn{4}{|c|}{ 2010-2011 papers } & \multicolumn{4}{|c|}{ 2005-2011 papers } & \multirow[b]{2}{*}{ Rank } \\
\hline & Int & $\operatorname{lnt} \mathrm{C}$ & ORP & Score & Int & Int C & ORP & Score & \\
\hline IBM & 25 & 0 & 0 & 25.0 & 30 & 1 & 0 & 30.5 & 1 \\
\hline Hewlett-Packard & 14 & 0 & 0 & 14.0 & 28 & 0 & 0 & 28.0 & 2 \\
\hline US Government & 1 & 0 & 0 & 1.0 & 25 & 0 & 1 & 26.0 & 3 \\
\hline General Electric & 10 & 2 & 0 & 11.0 & 23 & 3 & 0 & 24.5 & 4 \\
\hline Sasol & 14 & 0 & 0 & 14.0 & 14 & 0 & 0 & 14.0 & 5 \\
\hline Procter \& Gamble & 6 & 0 & 0 & 6.0 & 12 & 0 & 0 & 12.0 & 6 \\
\hline Merrill Lynch & 0 & 0 & 0 & 0.0 & 10 & 0 & 0 & 10.0 & 7 \\
\hline Smart0ps & 0 & 0 & 3 & 3.0 & 6 & 0 & 3 & 9.0 & 8 \\
\hline General Motors & 0 & 0 & 0 & 0.0 & 8 & 0 & 0 & 8.0 & 9 \\
\hline Intel & 3 & 0 & 0 & 3.0 & 8 & 0 & 0 & 8.0 & 9 \\
\hline John Deere & 0 & 0 & 3 & 3.0 & 4 & 0 & 4 & 8.0 & 9 \\
\hline Sabre & 0 & 0 & 0 & 0.0 & 8 & 0 & 0 & 8.0 & 9 \\
\hline Emptoris & 0 & 0 & 0 & 0.0 & 7 & 0 & 0 & 7.0 & 13 \\
\hline Sandia National Laboratories & 0 & 0 & 0 & 0.0 & 7 & 0 & 0 & 7.0 & 13 \\
\hline Motorola & 0 & 0 & 0 & 0.0 & 6 & 0 & 0 & 6.0 & 15 \\
\hline Netherlands Railways & 0 & 0 & 0 & 0.0 & 6 & 0 & 0 & 6.0 & 15 \\
\hline Bombardier Aerospace & 0 & 0 & 0 & 0.0 & 5 & 0 & 0 & 5.0 & 15 \\
\hline ExxonMobil & 5 & 0 & 0 & 5.0 & 5 & 0 & 0 & 5.0 & 15 \\
\hline Kimberly-Clark & 5 & 0 & 0 & 5.0 & 5 & 0 & 0 & 5.0 & 15 \\
\hline Marriott & 5 & 0 & 0 & 5.0 & 5 & 0 & 0 & 5.0 & 15 \\
\hline Xerox & 0 & 0 & 0 & 0.0 & 5 & 0 & 0 & 5.0 & 15 \\
\hline Bell Laboratories, Alcatel-Lucent & 0 & 0 & 0 & 0.0 & 4 & 0 & 0 & 4.0 & 22 \\
\hline Boeing & 0 & 0 & 0 & 0.0 & 4 & 0 & 0 & 4.0 & 22 \\
\hline CombineNet & 0 & 0 & 0 & 0.0 & 4 & 0 & 0 & 4.0 & 22 \\
\hline Delta & 0 & 0 & 0 & 0.0 & 4 & 0 & 0 & 4.0 & 22 \\
\hline The Rainmaker Group & 0 & 0 & 0 & 0.0 & 4 & 0 & 0 & 4.0 & 22 \\
\hline Zara & 4 & 0 & 0 & 4.0 & 4 & 0 & 0 & 4.0 & 22 \\
\hline AT\&T & 0 & 0 & 0 & 0.0 & 3 & 0 & 0 & 3.0 & 28 \\
\hline Caterpillar & 0 & 0 & 0 & 0.0 & 3 & 0 & 0 & 3.0 & 28 \\
\hline Citibank & 0 & 0 & 0 & 0.0 & 3 & 0 & 0 & 3.0 & 28 \\
\hline Cox Associates & 0 & 0 & 0 & 0.0 & 3 & 0 & 0 & 3.0 & 28 \\
\hline CSIRO Mathematical and Information Sciences & 0 & 0 & 0 & 0.0 & 3 & 0 & 0 & 3.0 & 28 \\
\hline Emeraldwise & 1 & 0 & 0 & 1.0 & 3 & 0 & 0 & 3.0 & 28 \\
\hline Ford & 0 & 0 & 0 & 0.0 & 3 & 0 & 0 & 3.0 & 28 \\
\hline Gapso Tecnologia da Decisao & 3 & 0 & 0 & 3.0 & 3 & 0 & 0 & 3.0 & 28 \\
\hline HD Supply Facilities Maintenance & 3 & 0 & 0 & 3.0 & 3 & 0 & 0 & 3.0 & 28 \\
\hline Institute of Information Technology & 0 & 0 & 0 & 0.0 & 3 & 0 & 0 & 3.0 & 28 \\
\hline Instituto Tecnologico Autonomo de Mexico & 3 & 0 & 0 & 3.0 & 3 & 0 & 0 & 3.0 & 28 \\
\hline J. D. Power and Associates & 0 & 0 & 0 & 0.0 & 3 & 0 & 0 & 3.0 & 28 \\
\hline Mckinsey \& Company & 2 & 0 & 0 & 2.0 & 3 & 0 & 0 & 3.0 & 28 \\
\hline New Brunswick Department of Transportation & 3 & 0 & 0 & 3.0 & 3 & 0 & 0 & 3.0 & 28 \\
\hline Norske Skog & 3 & 0 & 0 & 3.0 & 3 & 0 & 0 & 3.0 & 28 \\
\hline Philips Semiconductors & 0 & 0 & 0 & 0.0 & 3 & 0 & 0 & 3.0 & 28 \\
\hline ProRail & 0 & 0 & 0 & 0.0 & 3 & 0 & 0 & 3.0 & 28 \\
\hline Remsoft & 3 & 0 & 0 & 3.0 & 3 & 0 & 0 & 3.0 & 28 \\
\hline S.D. INDEVAL & 3 & 0 & 0 & 3.0 & 3 & 0 & 0 & 3.0 & 28 \\
\hline Schneider National & 3 & 0 & 0 & 3.0 & 3 & 0 & 0 & 3.0 & 28 \\
\hline Sun Microsystems & 3 & 0 & 0 & 3.0 & 3 & 0 & 0 & 3.0 & 28 \\
\hline Union Pacific Railroad & 0 & 0 & 0 & 0.0 & 3 & 0 & 0 & 3.0 & 28 \\
\hline
\end{tabular}

Table 2: The table lists visibility rankings for the top $\mathbf{4 9}$ nonacademic organizations with a seven-year score of 3.0 or greater. The score is the total number of citations for authors listing that organization as their primary affiliation in Interfaces (Int) and in the OR Practice section of Operations Research (ORP) plus half the number of unrefereed Interfaces columns (Int C). That is, Score $=\operatorname{Int}+\mathrm{ORP}+($ Int C)/2. The table shows organizational rankings and scores for 2005 through 2011 and scores for only 2010 to 2011. 


\begin{tabular}{|c|c|c|c|c|c|c|c|c|c|}
\hline \multirow[b]{2}{*}{ Organization } & \multicolumn{4}{|c|}{ 2010-2011 papers } & \multicolumn{4}{|c|}{ 2005-2011 papers } & \multirow[b]{2}{*}{ Rank } \\
\hline & Int & Int C & ORP & Score & Int & Int C & ORP & Score & \\
\hline US Government & 0.25 & 0.00 & 0.00 & 0.25 & 5.34 & 0.00 & 0.50 & 5.84 & 1 \\
\hline General Electric & 2.00 & 1.00 & 0.00 & 2.50 & 3.80 & 1.50 & 0.00 & 4.55 & 2 \\
\hline IBM & 2.60 & 0.00 & 0.00 & 2.60 & 4.05 & 1.00 & 0.00 & 4.55 & 2 \\
\hline Hewlett-Packard & 0.67 & 0.00 & 0.00 & 0.67 & 3.17 & 0.00 & 0.00 & 3.17 & 4 \\
\hline Intel & 0.50 & 0.00 & 0.00 & 0.50 & 2.67 & 0.00 & 0.00 & 2.67 & 5 \\
\hline Procter \& Gamble & 0.60 & 0.00 & 0.00 & 0.60 & 2.03 & 0.00 & 0.00 & 2.03 & 6 \\
\hline Merrill Lynch & 0.00 & 0.00 & 0.00 & 0.00 & 2.00 & 0.00 & 0.00 & 2.00 & 7 \\
\hline SmartCrane & 0.00 & 0.00 & 0.00 & 0.00 & 0.00 & 3.00 & 0.00 & 1.50 & 8 \\
\hline Smart0ps & 0.00 & 0.00 & 0.60 & 0.60 & 0.90 & 0.00 & 0.60 & 1.50 & 8 \\
\hline John Deere & 0.00 & 0.00 & 0.60 & 0.60 & 0.50 & 0.00 & 0.93 & 1.43 & 10 \\
\hline Sabre & 0.00 & 0.00 & 0.00 & 0.00 & 1.40 & 0.00 & 0.00 & 1.40 & 11 \\
\hline General Motors & 0.00 & 0.00 & 0.00 & 0.00 & 1.20 & 0.00 & 0.00 & 1.20 & 12 \\
\hline McKinsey \& Company & 0.53 & 0.00 & 0.00 & 0.53 & 1.03 & 0.00 & 0.00 & 1.03 & 13 \\
\hline Cox Associates & 0.00 & 0.00 & 0.00 & 0.00 & 1.00 & 0.00 & 0.00 & 1.00 & 14 \\
\hline Defence Science and Technology Organisation & 0.00 & 0.00 & 0.00 & 0.00 & 1.00 & 0.00 & 0.00 & 1.00 & 14 \\
\hline Delta & 0.00 & 0.00 & 0.00 & 0.00 & 1.00 & 0.00 & 0.00 & 1.00 & 14 \\
\hline ExxonMobil & 1.00 & 0.00 & 0.00 & 1.00 & 1.00 & 0.00 & 0.00 & 1.00 & 14 \\
\hline Greycon & 0.00 & 0.00 & 0.00 & 0.00 & 1.00 & 0.00 & 0.00 & 1.00 & 14 \\
\hline HD Supply Facilities Maintenance & 1.00 & 0.00 & 0.00 & 1.00 & 1.00 & 0.00 & 0.00 & 1.00 & 14 \\
\hline Marriott & 1.00 & 0.00 & 0.00 & 1.00 & 1.00 & 0.00 & 0.00 & 1.00 & 14 \\
\hline Schonberger and Associates & 1.00 & 0.00 & 0.00 & 1.00 & 1.00 & 0.00 & 0.00 & 1.00 & 14 \\
\hline Sun Microsystems & 1.00 & 0.00 & 0.00 & 1.00 & 1.00 & 0.00 & 0.00 & 1.00 & 14 \\
\hline The Center for Emergency Response Analytics & 0.00 & 0.00 & 0.00 & 0.00 & 1.00 & 0.00 & 0.00 & 1.00 & 14 \\
\hline Xerox & 0.00 & 0.00 & 0.00 & 0.00 & 1.00 & 0.00 & 0.00 & 1.00 & 14 \\
\hline
\end{tabular}

Table 3: The table lists yield rankings for the top 24 nonacademic organizations with a seven-year score of 1.0 or greater. The score is the weighted number of citations for authors listing that organization as their primary affiliation in Interfaces (Int) and in the OR Practice section of Operations Research (ORP) plus half the number of unrefereed Interfaces columns (Int C), where the weight allocates credit for each paper uniformly divided among the paper's authors. Thus, Score $=\operatorname{Int}+\mathrm{ORP}+(\operatorname{Int} \mathrm{C}) / 2$. The table shows organizational rankings and scores for 2005 through 2011 and scores for only 2010 to 2011.

greater, compared to only 24 nonacademic organizations in this listing. Thus, although there are roughly as many nonacademics and academics coauthoring papers in the INFORMS practice literature, it seems that nonacademics tend to collaborate with a larger number of coauthors on fewer total papers. That said, the metrics for the nonacademic organizations at the top of these rankings and the universities at the top of the university rankings are quite similar. For example, in combined academic and nonacademic rankings, IBM would still rank first in visibility, and the US Government would rank third in yield. What is different is that fewer nonacademic organizations publish at these levels.

One explanation for this difference is that more pressure to publish is on academics because their career advancement is often predicated on publication. In contrast, the pressure on nonacademics is often exactly the opposite; publication may have little to no impact on career advancement or, even worse, publication may be detrimental if it is seen as interfering with core activities and responsibilities. This brings us back to the purpose of these rankings: to recognize and encourage the publication of good OR/MS practice by those who actually practice OR/MS in the real world. After all, who should be better at describing OR/MS problems and how they are solved in the field than actual OR/MS practitioners?

As I said in the introduction, these rankings are motivated by the idea that recognition may encourage industry to publish more applications in the INFORMS practice literature. To those organizations on or near the top of these rankings, congratulations and keep it up! To those organizations that are not near the top, I hope these rankings are taken as a challenge that will spark the competitive spirit and spur publication. And, to all OR practitioners, it is my 
hope that these rankings provide your organizations with at least some incentive to support and encourage you to publish in the OR/MS practice literature.

\section{Acknowledgments}

My thanks to Jeff Camm, who first suggested I create a Rothkopf Rankings for nonacademic organizations during his tenure as Interfaces editor-in-chief. And my further thanks to Srinivas Bollapragada, the current Interfaces editor-in-chief, who nudged me to actually get it done. Any errors or omissions are, of course, solely my responsibility.

\section{References}

Fricker RD Jr (2009) Editorial: The eighth Rothkopf rankings of universities' contributions to the INFORMS practice literature. Interfaces 39(6):533-539.

Fricker RD Jr (2011) Editorial: The ninth Rothkopf rankings of universities' contributions to the INFORMS practice literature. Interfaces 41(6):590-598.
Rothkopf MH (1996) Editorial: Which universities contribute to the practice literature? The first Interfaces ranking. Interfaces 26(2):16-21.

Rothkopf MH (1997) Editorial: Which universities contribute to the practice literature? The second Interfaces ranking. Interfaces 27(4):19-22.

Rothkopf MH (1999) Editorial: The third Interfaces ranking of universities' contributions to the practice literature. Interfaces 29(6):107-111.

Rothkopf MH (2002) Editorial: Leveling the field? The fourth Interfaces ranking of universities' contributions to the practice literature. Interfaces 32(2):23-27.

Rothkopf $\mathrm{MH}$ (2004) Editorial: The fifth Interfaces ranking of universities' contributions to the practice literature. Interfaces 34(2):135-138.

Rothkopf MH (2005) Editorial: The sixth Interfaces ranking of universities' contributions to the practice literature. Interfaces 35(5):425-428.

Rothkopf MH (2007) Editorial: The seventh Interfaces ranking of universities' contributions to the practice literature. Interfaces 37(6):566-569. 